\title{
Relationship Between Endothelial Function and Coronary Risk Factors in Patients With Stable Coronary Artery Disease
}

\author{
Cevat Kirma, MD; Mustafa Akcakoyun, MD; Ali Metin Esen, MD; \\ Irfan Barutcu, MD; Osman Karakaya, MD; Mustafa Saglam, MD; \\ Ramazan Kargin, MD; Muhsin Turkmen, MD; Bilal Boztosun, MD; \\ Akın Izgi, MD; Kenan Sonmez, MD
}

\begin{abstract}
Background Results of experimental and clinical studies suggest that both coronary artery disease (CAD) itself and its traditional risk factors lead to endothelial dysfunction. The aim of the present study was to determine which CAD risk factors sustain their contribution to endothelial dysfunction despite the presence of established CAD.

Methods and Results The study group comprised 150 patients with CAD. Using a high-resolution ultrasound, the diameter of the brachial artery at rest and during reactive hyperemia (flow-mediated dilatation, FMD\%: endothelial-dependent stimulus to vasodilatation), as well as after sublingual administration of nitroglycerin (NTG\%: endothelium-independent vasodilatation), was measured. The relationship between FMD\% and coronary risk factors [diabetes mellitus (DM), total cholesterol, high-density lipoprotein-cholesterol, low-density lipoproteincholesterol, triglycerides, age, family history of premature atherosclerosis, smoking, hypertension (HT), body mass index (BMI)] was investigated. In univariate analysis there was an inverse relationship between FMD\% and age $(r=-0.300, p<0.001)$, and BMI $(r=-0.230, p<0.005)$ and FMD\% was significantly lower in diabetic patients when compared to non-diabetic patients $(\mathrm{p}<0.001)$. In stepwise multivariate regression analysis; FMD still correlated with DM and advanced age, but not with BMI $\beta=0.065, p<0.001, \beta=-0.001 \mathrm{p}=0.002, \beta=-0.087, \mathrm{p}<0.284$, respectively). FMD\% was found to be not associated with hypercholesterolemia, family history of premature atherosclerosis, HT and smoking.

Conclusion Only aging and DM were independently associated with endothelial dysfunction in patients with established CAD. (Circ J 2007; 71: 698-702)
\end{abstract}

Key Words: Coronary artery disease; Coronary risk factors; Endothelial function

$\mathbf{T}$ he vascular endothelium plays an integral role not only in regulation of vascular tonus, but also in prevention and formation of thrombus and inflammation! It is known that endothelial dysfunction is associated with coronary risk factors and atherosclerosis, and has a close pathophysiological relation with acute coronary syndromes ${ }^{2-4}$ Endothelial dysfunction has been shown in patients with documented atherosclerosis, but it is also an early step in the pathogenesis of the atherosclerotic cascade ${ }^{5-7}$ Among various methods to assess endothelial function, endothelium-dependent vasodilatation (EDV) is a noninvasive, highly reproducible, simple method based on high-sensitivity ultrasound waves?,8 In this study we assessed the relationship between EDV in systemic arteries and coronary risk factors in patients with documented coronary artery disease (CAD).

(Received August 1, 2006; revised manuscript received January 22, 2007; accepted February 9, 2007)

Department of Cardiology, Kartal Kosuyolu Yuksek Ihtisas Education and Research Hospital, Istanbul, Turkey

Mailing address: Ali Metin Esen, MD, Kazim Karabekir Caddesi, Ifakat Hanim Apt., No.3, B Daire:26 Erenkoy, Istanbul, Turkey. E-mail: ameoz@superonline.com

\begin{abstract}
Methods
Patient Population

One hundred and fifty patients with angiographically proven CAD (103 males, 47 females), age ranging between 29 and 78 years (mean: 58 \pm 10 ), were recruited. CAD was defined as the presence of angiographically demonstrated $\geq 70 \%$ stenosis in at least 1 major epicardial coronary artery. Hypertension (HT) was defined as blood pressure $\geq 140$ / $90 \mathrm{mmHg}$ or use of antihypertensive drugs and diabetes mellitus (DM) as fasting blood glucose level $\geq 126 \mathrm{mg} / \mathrm{dl}$ or use of antidiabetic agents. All study subjects underwent a complete physical examination, and biochemical, electrocardiographic and body mass index (BMI) measurements. Vascular endothelial function in the brachial artery was measured by the flow-mediated dilatation (FMD) technique. Patients with acute coronary syndromes, severe left ventricular dysfunction (ejection fraction $<35 \%$ ) or old myocardial infarction were excluded from the study.
\end{abstract}

\section{Vascular Study}

Each subject was studied in the morning, after abstaining from alcohol, caffeine and tobacco, as well as food, within $8 \mathrm{~h}$ before the study. High-resolution echocardiography Doppler ultrasound (Technos MPX ultrasound ESOTA Inc) with an $8.0 \mathrm{MHz}$ transducer was used to measure the 
Table 1 Demographic Characteristics of the Study Population

\begin{tabular}{lccl}
\hline \hline & $\begin{array}{c}\text { Female } \\
(n=47)\end{array}$ & $\begin{array}{c}\text { Male } \\
(n=103)\end{array}$ & p value \\
\hline Age $($ years) & $60.7 \pm 9.1$ & $57.0 \pm 11.1$ & 0.03 \\
TC level $(\mathrm{mg} / \mathrm{dl})$ & $207.0 \pm 41.5$ & $194.9 \pm 53.4$ & 0.15 \\
TG level $(\mathrm{mg} / \mathrm{dl})$ & $168.7 \pm 67.7$ & $160.4 \pm 97.5$ & 0.57 \\
HDL-C level $(\mathrm{mg} / \mathrm{dl})$ & $47.3 \pm 10.4$ & $44.2 \pm 12.0$ & 0.12 \\
LDL-C level $(\mathrm{mg} / \mathrm{dl})$ & $125.7 \pm 38.7$ & $121.5 \pm 46.7$ & 0.58 \\
TC/HDL-C ratio & $4.6 \pm 1.3$ & $4.7 \pm 1.8$ & 0.6 \\
BMI & $28.5 \pm 4.9$ & $26.9 \pm 4.3$ & 0.06 \\
DM $(\%)$ & 42.6 & 21.4 & 0.007 \\
History of smoking $(\%)$ & 19.1 & 56.3 & 0.0001 \\
HT $(\%)$ & 80.9 & 42.7 & 0.001 \\
Family history $(\%)$ & 40.4 & 34.0 & 0.26 \\
\hline
\end{tabular}

TC, total cholesterol; TG, triglyceride; HDL-C, high-density lipoprotein-cholesterol; LDL-C, low-density lipoprotein-cholesterol; $B M I$, body mass index; DM, diabetes mellitus; HT, hypertension.

Table 2 Brachial Artery Measurements

\begin{tabular}{lccc}
\hline \hline & $\begin{array}{l}\text { Female } \\
(n=47)\end{array}$ & $\begin{array}{c}\text { Male } \\
(n=103)\end{array}$ & p value \\
\hline Basal diameter $(\mathrm{mm})$ & $3.7 \pm 0.5$ & $4.1 \pm 0.7$ & 0.008 \\
Diameter after stimulation (mm) & $3.9 \pm 0.5$ & $4.4 \pm 0.7$ & 0.006 \\
Percent of flow-mediated dilatation (\%) & $5.4 \pm 1.9$ & $5.7 \pm 1.4$ & $N S$ \\
Diameter after $N T G($ mm) & $4.1 \pm 0.5$ & $4.6 \pm 0.7$ & $<0.001$ \\
NTG-dependent vasodilatation $(\%)$ & $10.5 \pm 2.6$ & $10.3 \pm 2.6$ & $N S$ \\
\hline
\end{tabular}

NS, statistically not significant; NTG, nitroglycerine.

flow velocity and diameter of the right brachial arteries. In all studies, scans were taken at rest, during reactive hyperemia (FMD\%: endothelial-dependent stimulus to vasodilatation), again at rest and after sublingual nitroglycerin (NTG\%: endothelium-independent vasodilatation). The inter- and intra-observer variabilities for repeated measurements are $0.13 \pm 0.06$ and $0.14 \pm 0.02 \mathrm{~mm}$, respectively, in our laboratory.

Each study subject rested quietly for $10 \mathrm{~min}$ before the scan, then after being placed in the appropriate position, the skin was marked and arterial flow velocity was measured at rest using a pulsed Doppler signal at $60^{\circ}$ in the center of the artery. Blood flow through the brachial artery was altered with an occluding cuff placed on the forearm $8 \mathrm{~cm}$ distal to the site of brachial artery measurement 5 By inflating the cuff to $250-300 \mathrm{mmHg}$, distal circulation was arrested and flow was reduced through the brachial artery measured proximal to the cuff. By deflating the cuff after $5 \mathrm{~min}$ of inflation, flow through the brachial artery was increased (reactive hyperemia). The brachial artery was scanned continuously $30 \mathrm{~s}$ before and $90 \mathrm{~s}$ after cuff deflation, then 10 min later, a second rest scan was recorded. NTG (400 g) was then administered sublingually, and the artery was scanned $5 \mathrm{~min}$ later.

All images were analyzed by 2 observers who were unaware of the clinical details. Artery diameter measurements were made at end-diastole (peak of $\mathrm{R}$ wave on electrocardiogram) using electronic calipers. Five cardiac cycles were analyzed, and measurements were averaged. Brachial artery diameter measurements after reactive hyperemia were taken $60 \mathrm{~s}$ after cuff deflation. FMD was calculated as the percent increase in arterial diameter during reactive hyperemia vs the corresponding rest value. Brachial artery diameter measurements after NTG were taken after its administration and nitroglycerin-induced dilatation was calculated as the percent increase in arterial diameter after

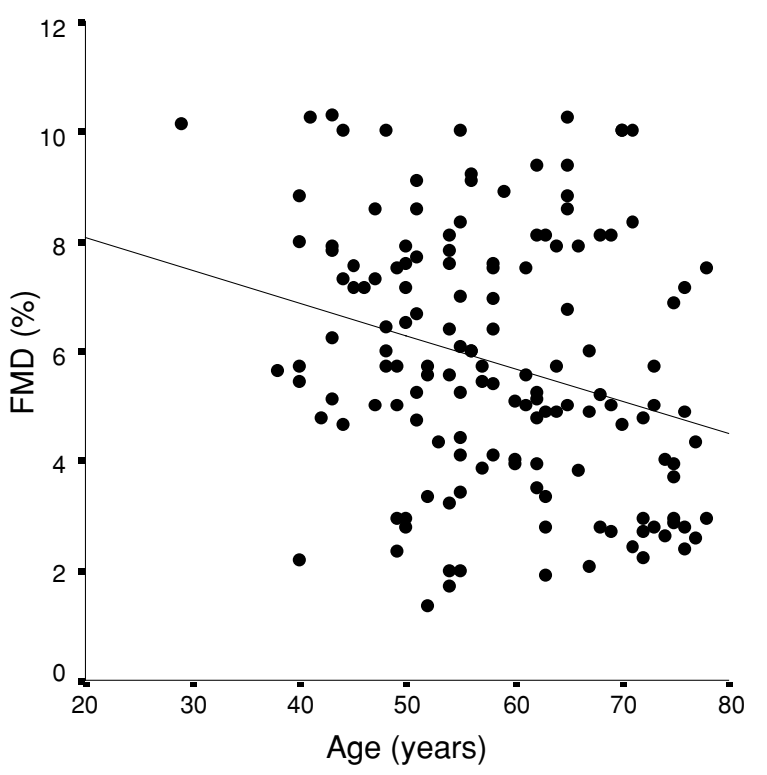

Fig 1. Relationship between flow-mediated dilatation (FMD\%) and age $(r=-0.300, p<0.001)$.

NTG vs the corresponding rest value.

\section{Statistical Analysis}

Statistical analyses were performed with SPSS-11.5 for Windows (Chicago, IL, USA). Continuous variables are displayed as mean \pm standard deviation and categorical ones as percentage. Pearson's correlation test was performed between variables and the Mann-Whitney U-test was used to compare the means of 2 non-homogeneous groups. Multiple stepwise regression analysis was used to assess the relationship between coronary risk factors and FMD\%. A value 


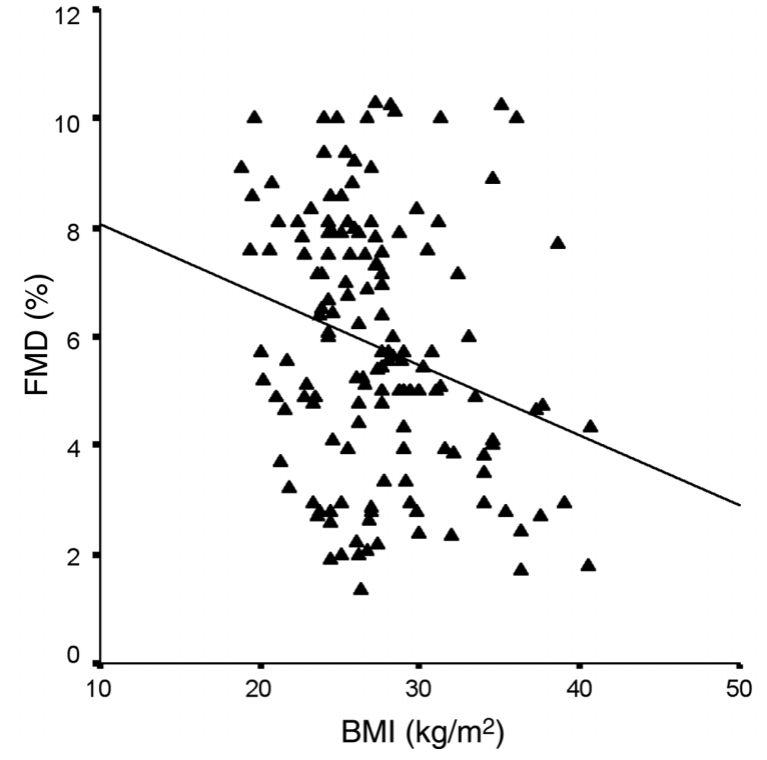

Fig 2. Relationship between flow-mediated dilatation (FMD\%) and body mass index (BMI) $(r=-0.230, p=0.005)$.

of $p<0.05$ on the 2 -tail test was considered statistically significant.

\section{Results}

\section{Patient Population (Table 1)}

Of the 150 patients, $68 \%$ were men and $32 \%$ were women, with respective mean ages of $57.0 \pm 11.0$ years and $60.7 \pm 9.1$ years; $54 \%$ had HT, $28 \%$ had DM, $36 \%$ had a family history of CAD and $45 \%$ were smokers; 70 patients had single-vessel disease, 56 had 2-vessel disease, and 24 had 3-vessel disease. In the diabetic population only 21 patients were using oral antidiabetic agents, such as metformin $(n=11)$, gliclazide $(n=7)$ or glimepiride $(n=3)$. In the hypertensive population 50 patients were using an oral antihypertensive agent, including diuretics $(\mathrm{n}=21)$, angiotensin converting enzyme inhibitors $(n=13)$, angiotensin II receptor blockers $(n=11)$ or calcium antagonists $(n=5)$. In addition, nearly $25 \%$ of the study population were using cholesterollowering drugs such as atorvastatin $(n=14)$, simvastatin $(n=10)$, pravastatin $(n=6)$, and fenofibrate $(n=5)$. The mean BMI of the participants was $27.4 \pm 4.5 \mathrm{~kg} / \mathrm{m}^{2}$, mean total cholesterol (TC) level was $198 \pm 50 \mathrm{mg} / \mathrm{dl}$, low-density lipoprotein (LDL)-cholesterol level was $122 \pm 44 \mathrm{mg} / \mathrm{dl}$, high-density lipoprotein (HDL)-cholesterol level was $45 \pm 11 \mathrm{mg} / \mathrm{dl}$, triglyceride (TG) level was $163 \pm 89.3 \mathrm{mg} / \mathrm{dl}$, and the TC/ HDL ratio was $4.7 \pm 1.8 \mathrm{mg} / \mathrm{dl}$.

\section{Vascular Study (Table 2)}

The mean basal brachial artery diameter was $4.0 \pm 0.7 \mathrm{~mm}$, mean FMD\% was $5.8 \pm 0.2 \%$ and mean sublingual NTGdependent vasodilatation was $10 \pm 0.2 \%$.

\section{Risk Factors and Vascular Results}

In the univariate analysis there was an inverse relationship between FMD\% and age $(\mathrm{r}=-0.300, \mathrm{p}<0.001)$, and BMI $(r=-0.230, p<0.005)$ and FMD\% was significantly lower in diabetic patients when compared with non-diabetic patients $(\mathrm{p}<0.001)$ (Figs 1-3). However, there was no relationship between HT, presence of family history, smoking

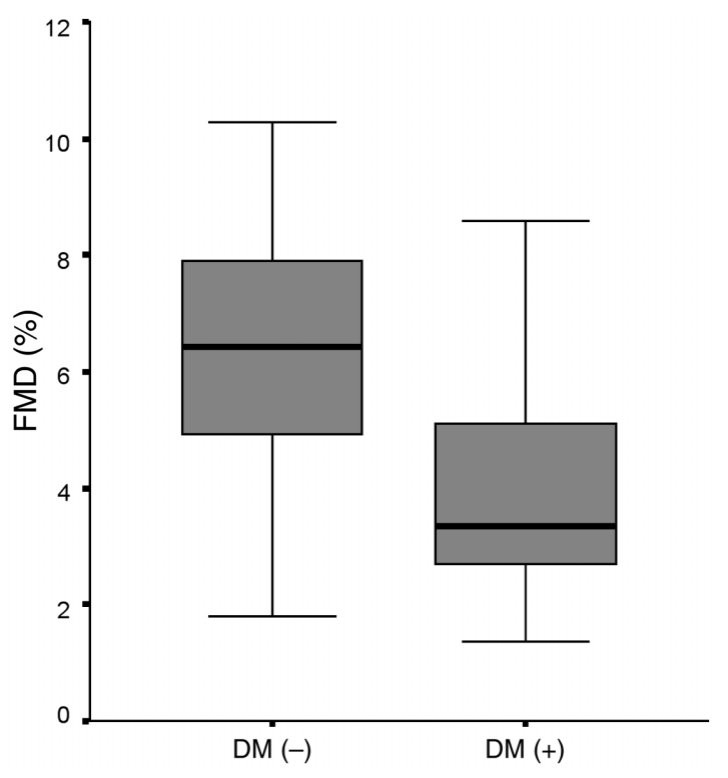

Fig 3. Comparison of flow-mediated dilatation (FMD\%) in nondiabetic and diabetic patients $(\mathrm{p}<0.001)$. DM, diabetes mellitus.

status, TC, TG, LDL-cholesterol, HDL-cholesterol or the TC/HDL ratio. In the multiple stepwise regression analysis, the relationship between FMD $\%$ and age $\beta=-0.001, p=$ 0.002 ) and the presence of DM $\beta=0.065, p<0.001$ ) continued, whereas the relationship with BMI disappeared $\beta=$ $-0.087, \mathrm{p}<0.284)$.

\section{Discussion}

Many studies have investigated the relationship between coronary risk factors and endothelial function. Celermajer et $\mathrm{al}^{8}$ investigated the relationship and interaction between coronary risk factors and endothelial function in 500 (mean age $36 \pm 15$ ) asymptomatic adults. In their univariate analysis they found an inverse relationship between FMD\% and hyperlipidemia, smoking, blood pressure, male sex, family history and larger vascular diameter. In their multiple stepwise regression analysis the relationship between FMD\% and smoking, male sex, and larger vascular diameter continued, but not with hyperlipidemia, blood pressure or family history. In that study patients with HT and DM were excluded. Herrington et $\mathrm{al}^{9}$ showed that age and male sex were strong parameters for determining FMD\% in a population of 4,040 patients who were mostly elderly, but they did not investigate coronary risk factors.

Benjamin et $\mathrm{a}^{10}$ investigated the relationship between coronary risk factors and endothelial function in 2,883 patients and found a relationship between FMD\% and female sex, exercise and increased heart rate, and an inverse relation with old age, HT, BMI, lipid-lowering therapy and smoking. In their multivariate analysis the effect of BMI and female sex continued for FMD\%. However, in our study we established an independent relationship between FMD\% and age and DM in the presence of CAD. Tanriverdi et al ${ }^{11}$ have suggested that FMD is significantly lower in smokers than nonsmokers among subjects with normal coronary arteries. In addition, Ishibashi et al ${ }^{12}$ used plethysmography to measure reactive hyperemia in healthy subjects with multiple cardiovascular risk factors and found that the number of risk factors significantly correlated with the duration of 
reactive hyperemia, suggesting that endothelial dysfunction increases with the number of risk conditions clustering in a single individual. However, our study was in part different from the aforementioned studies because we intended to investigate the contribution of cardiovascular risk factors to the degree of endothelial dysfunction. Also, in contrast to the previous reports, we included patients with established CAD not normal coronary arteries. Terawa et al ${ }^{13}$ investigated the effect of alcohol consumption on FMD and reported that it was independently associated with endothelial dysfunction in 108 men with CAD. However, in our study only 6 patients had a history of regular alcohol consumption, so we could not investigate the effect of alcohol consumption on FMD. In the study by Terawa et al only the effect of alcohol consumption, not of the other cardiovascular risk factors, on FMD was studied, whereas in the present study we investigated the relationship between multiple risk factors including aging, smoking, HDL-cholesterol, LDL-cholesterol, TC, TG, obesity, DM, HT, family history and endothelial dysfunction in a patient population with documented stable CAD.

It has been shown that endothelial function is impaired in the elderly9,14 Although the mechanism is not clear, it has been proposed that the increase in free oxygen radicals with aging inactivates nitric oxide or has a direct toxic effect on the endothelium ${ }^{15}$ In our study we showed that aging is independently associated with endothelial dysfunction even in the presence of CAD, which suggests an effect of aging on endothelial dysfunction. Hirai et $\mathrm{al}^{16}$ have shown that both acute and chronic hyperglycemia and impaired glucose tolerance cause endothelial dysfunction, and in a recent study it was shown that even transient hyperglycemia induced with oral glucose in non-diabetic subjects impairs FMD ${ }^{17}$ Several different mechanisms have been proposed as explanation 18,19 One of the major findings of our study is that DM still continues to be an independent factor effecting endothelial function in patients with CAD. As well, in our study the mean glucose value in patients with DM was $154 \pm 40.55 \mathrm{mg} / \mathrm{dl}$, which is an acceptable level for glycemic control, so our results suggests that DM has a relationship with endothelial function in patients with $\mathrm{CAD}$ even when good glycemic control is achieved.

It is known that obesity impairs endothelial function whereas weight loss improves it. ${ }^{20-22}$ The reason is multifactorial and may in part be associated with oxidative stress and systemic inflammation. In our study, we found a weak inverse relationship between BMI and FMD\%, but this lost significance in the multivariate analysis. A possible reason for this weak relation might have been that our population had a relatively low BMI because only $25 \%$ of them had a BMI $>30 \mathrm{~kg} / \mathrm{m}^{2}$.

There are many studies showing a connection between HT and endothelial function ${ }^{18-20}$ Antihypertensive treatment improves endothelial function, leading to less cardiac events ${ }^{24,25}$ Although the mechanism of the relationship between HT and endothelial dysfunction is unknown, it has been proposed that endothelial dysfunction itself causes $\mathrm{HT}^{26}$ In our study we did not find a relationship between HT and endothelial function, which may have resulted from the patients having appropriate antihypertensive treatment.

Although endothelial dysfunction caused by smoking is multifactorial, there is sufficient evidence that free oxygen radicals have a potential role!1,27,28 Both passive and active smoking causes endothelial dysfunction, $8,29,30$ In contrast to previous studies we found no relationship between smoking and endothelial dysfunction; however, almost all of the present patients had quit smoking after clinical and/or angiographic diagnosis of CAD. Benjamin et $\mathrm{al}^{10}$ found that FMD\% was better in smokers who did not smoke within the $6 \mathrm{~h}$ prior to the study hours than in those who did smoke.

It has been shown that elevated blood cholesterol impairs endothelial function ${ }^{31}$ and the lack of this association in our study may be related to the characteristics of our study population because $25 \%$ were using cholesterol-lowering drugs.

\section{Study Limitations}

Because the study subjects had CAD they were using medications that have some effect on endothelial function and could have partly affected the FMD results. However, all drugs were ceased at least $24 \mathrm{~h}$ before the measurement of FMD, so we consider that drug effects on FMD were probably minimal. In addition, all patients did not undergo an oral glucose tolerance test; however, approximately $40 \%$ of population was already diabetic and none of the non-diabetic patient had symptoms or clinical finding of diabetes. Moreover, the fasting blood glucose level of these patients was less than $110 \mathrm{mg} / \mathrm{dl}$.

\section{Conclusion}

The relationship between coronary risk factors and endothelial dysfunction has been shown in many studies, but in the present study using multivariate regression analysis we investigated the relationship between multiple risk factors and endothelial dysfunction in a patient population with documented stable CAD. We found that only aging and DM were independently associated with endothelial dysfunction in the presence of CAD. Obviously, these results need to be validated with further large-scale and long-term studies.

\section{References}

1. Vane JR, Anggard EE, Botting RM. Regulatory functions of the vascular endothelium. $N$ Engl J Med 1990; 323: 27-36.

2. Clinical manifestations of endothelial dysfunction. In: Loscalzo J, Schafer AI, editors. Thrombosis and Hemorrhage. Philadelphia, PA: Lippincott Williams \& Wilkins; 2002; 685-706.

3. Takase B, Hamabe A, Satomura K, Akima T, Uehata A, Matsui T, et al. Coronary artery spasm and the polymorphisms of the endothelial nitric oxide synthase gene. Circ J 2006; 70: 409-413.

4. Martinovic I, Abegunewardene N, Seul M, Vosseler M, Horstick G, Buerke M, et al. Elevated monocyte chemoattractant protein-1 serum levels in patient at risk of coronary artery disease. Circ J 2005; 69: 1484-1489.

5. Ludmer PL, Selwyn AP, Shook TL, Wayne RR, Mudge GH, Alexander RW, et al. Paradoxical vasoconstriction induced by acetylcholine in atherosclerotic coronary arteries. N Engl J Med 1986; 315: $1046-1051$.

6. Ross R. The pathogenesis of atherosclerosis- an update. $N$ Engl $J$ Med 1986; 8: 488-500.

7. Celermajer DS, Sorensen KE, Gooch VM, Spiegelhalter DJ, Miller OI, Sullivan ID, et al. Non-invasive detection of endothelial dysfunction in children and adults at risk of atherosclerosis. Lancet 1992; 340: $1111-1115$.

8. Celermajer DS, Sorensen KE, Bull C, Robinson J, Deanfield JE. Endothelium-dependent dilation in the systemic arteries of asymptomatic subjects relates to coronary risk factors and their interaction. J Am Coll Cardiol. 1994; 24: 1468-1474.

9. Herrington DM, Fan L, Drum M, Riley WA, Pusser BE, Crouse JR, et al. Brachial flow-mediated vasodilator responses in populationbased research: Methods, reproducibility and effects of age, gender and baseline diameter. J Cardiovasc Risk 2001; 8: 319-328.

10. Benjamin EJ, Larson MG, Mitchell GF, Vasan RS, Keaney JF Jr, 
Lehman BT, et al. Clinical correlates and heritability of flow-mediated dilation in the community: The Framingham Heart Study. Circulation 2004; 109: 613-619.

11. Tanrıverdi H, Evrengul H, Kuru O, Tanriverdi S, Seleci D, Enli Y, et al. Cigarette smoking induced oxidative stress may impaire endothelial function and coronary blood flow in angiographically normal coronary arteries. Circ J 2006; 70: 593-599.

12. Ishibashi $\mathrm{Y}$, Takahashi N, Shimada T, Sugamori T, Sakane T, Umeno $\mathrm{T}$, et al. Short duration of reactive hyperemia in the forearm of subjects with multiple cardiovascular risk factors. Circ J 2006; 70: $115-123$.

13. Teragawa H, Fukuda Y, Matsuda K, Higashi Y, Yamagata T, Matsuura $\mathrm{H}$, et al. Effect of alcohol consumption on endothelial function in men with coronary artery disease. Atherosclerosis 2002; 165: $145-152$.

14. Celermajer DS, Sorensen KE, Spiegelhalter DJ, Georgakopoulos D, Robinson J, Deanfield JE. Aging is associated with endothelial dysfunction in healthy men years before the age-related decline in women. J Am Coll Cardiol. 1994; 24: 471-476.

15. Gryglewski RJ, Palmer RM, Moncada S. Superoxide anion is involved in the breakdown of endothelium-derived vascular relaxing factor. Nature (Lond) 1986; 320: 454-456.

16. Hirai N, Kawano H, Hirashima O, Motoyama T, Moriyama Y, Sakamoto T, et al. Insulin resistance and endothelial dysfunction in smokers: Effects of vitamin C. Am J Physiol Heart Circ Physiol 2000; 279: H1172-H1178.

17. Title LM, Cummings PM, Giddens K, Nassar BA. Oral glucose loading acutely attenuates endothelium-dependent vasodilation in healthy adults without diabetes: An effect prevented by vitamins $\mathrm{C}$ and E. J Am Coll Cardiol 2000; 36: 2185-2191.

18. Bucala R, Tracey KJ, Cerami A. Advanced glycosylation products quench nitric oxide and mediate defective endothelium-dependent vasodilatation in experimental diabetes. J Clin Invest 1991; 87: 432 438.

19. Tesfamariam B. Free radicals in diabetic endothelial cell dysfunction. Free Radic Biol Med 1994; 16: 383-391.

20. Tounian P, Aggoun Y, Dubern B, Varille V, Guy-Grand B, Sidi D, et al. Presence of increased stiffness of the common carotid artery and endothelial dysfunction in severely obese children: A prospective study. Lancet 2001; 358: 1400-1404.

21. Ziccardi P, Nappo F, Giugliano G, Esposito K, Marfella R, Cioffi M, et al. Reduction of inflammatory cytokine concentrations and improvement of endothelial functions in obese women after weight loss over one year. Circulation 2002; 105: 804-809.

22. Perticone F, Ceravolo R, Candigliota M, Ventura G, Iacopino S, Sinopoli F, et al. Obesity and body fat distribution induce endothelial dysfunction by oxidative stress: Protective effect of vitamin C. Diabetes 2001; 50: 159-165.

23. Gokce N, Holbrook M, Duffy SJ, Demissie S, Cupples LA, Biegelsen $\mathrm{E}$, et al. Effects of race and hypertension on flow-mediated and nitroglycerin-mediated dilation of the brachial artery. Hypertension 2001; 38: $1349-1354$.

24. Taddei S, Virdis A, Ghiadoni L, Sudano I, Salvetti A. Effects of antihypertensive drugs on endothelial dysfunction: Clinical implications. Drugs 2002; 62: 265-284.

25. Modena MG, Bonetti L, Coppi F, Bursi F, Rossi R. Prognostic role of reversible endothelial dysfunction in hypertensive postmenopausal women. J Am Coll Cardiol 2002; 40: 505-510.

26. Taddei S, Virdis A, Mattei P, Ghiadoni L, Sudano I, Salvetti A. Defective L-arginine-nitric oxide pathway in offspring of essential hypertensive patients. Circulation 1996; 94: 1298-1303.

27. Morrow JD, Frei B, Longmire AW, Gaziano JM, Lynch SM, Shyr Y, et al. Increase in circulating products of lipid peroxidation (F2isoprostanes) in smokers: Smoking as a cause of oxidative damage. N Engl J Med 1995; 332: 1198-1203.

28. Murohara T, Kugiyama K, Ohgushi M, Sugiyama S, Yasue H. Cigarette smoke extract contracts isolated porcine coronary arteries by superoxide anion-mediated degradation of EDRF. Am J Physiol 1994; 266: H874-H880.

29. Esen AM, Barutcu I, Acar M, Degirmenci B, Kaya D, Turkmen M, et al. Effect of smoking on endothelial function and wall thickness of brachial artery. Circ J 2004; 68: 1123-1127.

30. Barutcu I, Esen AM, Degirmenci B, Acar M, Kaya D, Turkmen M, et al. Acute cigarette smoking-induced hemodynamic alterations in the common carotid artery-a transcranial Doppler study. Circ J 2004; 68: $1127-1131$.

31. Sorensen KE, Celermajer DS, Georgakopoulos D, Hatcher G, Betteridge DJ, Deanfield JE. Impairment of endothelium-dependent dilatation is an early event in children with familial hypercholesterolemia and is related to the lipoprotein (a) level. J Invest 1994; 93: 5055 . 